\title{
Dielectric Constant of Deuterium Oxide
}

\author{
Cyrus G. Malmberg
}

An equal ratio-arm, capacitance-conductance bridge operated at frequencies below 100 kilocycles per second was used to measure the dielectric constant of deuterium oxide with an accuracy of 0.1 percent or better in the range $4^{\circ}$ to $100^{\circ} \mathrm{C}$. A value of 77.94 was found for the dielectric constant at $25^{\circ} \mathrm{C}$. The data fit the relation

$$
\epsilon=87.48_{2}-(0.40509) t+\left(9.638 \times 10^{-4}\right) t^{2}-\left(1.333 \times 10^{-6}\right) t^{3},
$$

with a maximum deviation of less than 0.01 unit in dielectric constant. These values were obtained by using a sample having a deuterium oxide content of 99.38 mole percent. Deviation of these values from those for pure deuterium oxide, as a result of isotopic contamination, is estimated to be less than 0.005 unit. Some aspects of the temperature dependence of the dielectric constant and of that of a macroscopic polarization are discussed.

\section{Introduction}

Only a few determinations of the dielectric constant of deuterium oxide have been reported in the literature, and of these only Wyman and Ingalls [1] ${ }^{1}$ report static values obtained over an extended range of temperature. Their work included a direct comparison with water from $0^{\circ}$ to $100^{\circ} \mathrm{C}$, and the values obtained were dependent on Wyman's [2] value for water at $25^{\circ} \mathrm{C}$.

The present investigation was designed to redetermine the dielectric constant of deuterium oxide from $4^{\circ}$ to $100^{\circ} \mathrm{C}$ with an accuracy of 0.1 percent or better. The measurements were made with a low-frequency bridge, equipped with a Wagner ground, and a three-terminal test cell. They were essentially absolute in that no standard medium other than air was required for calibrating the cell.

\section{Materials}

The deuterium oxide was a sample originally stated to be 99.5 mole percent deuterium oxide. Mass spectrographic analysis indicated that the oxygen content was 0.9 mole percent $\mathrm{O}^{18}$. After distillation of the sample in a closed system and measurement of its dielectric constant, the density of the sample was found to be $1.1045_{5} \mathrm{~g} / \mathrm{cm}$ at $25^{\circ} \mathrm{C}$. When corrected for the excess $\mathrm{O}^{18}$, this density corresponds to a deuterium oxide content of 99.38 mole percent.

\section{Experimental Techniques}

The a-c bridge was of the equal ratio-arm, capacitance-conductance type employing a Wagner ground to permit proper use of the guarded test cell. With minor exceptions, this apparatus and the techniques employed in the present measurements were the same as previously described [3, 4]. All measurements were made at frequencies in the range 3 to 96 $\mathrm{kc}$ in a cell that was used for a previous determination on ordinary water [4] (cell A). To control its temperature more simply, this cell was fitted with a

\footnotetext{
${ }_{1}^{1}$ Figures in brackets indicate the literature references at the end of this paper.
}

leakproof cover to allow its total immersion in the bath media, with control to better than $0.01^{\circ} \mathrm{C}$.

Determinations of the air capacity of the cell were made both before and during the measurements on $\mathrm{D}_{2} \mathrm{O}$ as part of stepwise recalibrations of the fundamental interval of the standard capacitor. These measurements and check measurements with ordinary water as the dielectric media indicate a very slight change of 0.01 percent in the replaceable capacity of the cell from that previously found. The long-term stability indicated by these checks also serves for purposes of comparison to relate more closely the present measurements on deuterium oxide with those previously made on water.

Because excessive conductance of the sample can be a major source of error, it is particularly desirable to eliminate ionizable impurity in the material under study. The apparatus shown in figure 1 was de-

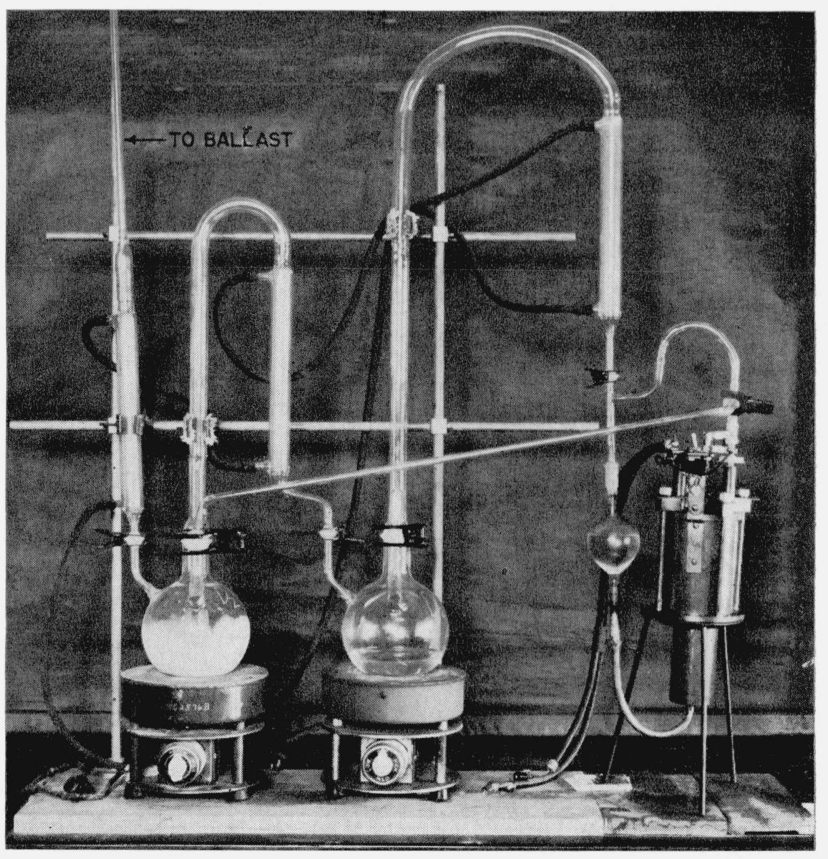

Figure 1. Arrangement of cell $A$ and the two-stage still designed for separation of ionizable impurity from the sample of $\mathrm{D}_{2} \mathrm{O}$. 
signed for this purpose, in view of the limited sample available. It consists of the two simple Pyrex-glass evaporators and condensers connected in tandem with the cell. The output of the second stage is fed to the reservoir of the cell, and after passing through the cell is returned to the evaporator of the first stage. Isolation of the system is accomplished by connection to a 20-liter atmospheric ballast, through a reflux condenser from the first stage.

The two stages were required to free the distillate of volatile acidic and basic impurities, such as carbon dioxide and deutero-ammonia $\left(\mathrm{ND}_{3}\right)$. This was accomplished by placing $1 \mathrm{~g}$ of calcium oxide formed from the carbonate in the first evaporator and $2 \mathrm{~g}$ of phosphoric anhydride in the second evaporator. Approximately $600 \mathrm{ml}$ of sample was then added to stage 1 , and half of this was distilled into stage 2 to produce alkaline and acid solutions for respective conversion of volatile acidic and basic impurities to nonvolatile compounds. As the system was effectively closed, redistillation and recirculation through the cell could continue until minimum conductivity or that of a degree desired had been achieved. Through use of a temporary heating coil surrounding the cell, the contents could be maintained at the boiling point to aid in leaching out the cell and to permit adjustment of the final level as desired in its reservoir. Boiling the sample in the cell also eliminated the tendency for bubbles to form between the electrodes.

Contamination by water vapor and carbon dioxide was avoided by maintaining an atmosphere of nitrogen over the sample in the cell during the course of the measurements of dielectric constant. Following a set of measurements the cell was reinserted in the distillation train and refilled for companion measurements. During the various stages of "processing" the cell, the minimum conductivity observed at $25^{\circ} \mathrm{C}$ was $0.050 \mu \mathrm{mho} / \mathrm{cm}$.

Determinations of the dielectric constant of the deuterium oxide were made at 5-degree intervals. For each temperature the cell was refilled at least once and the measurements repeated.

Conditions of corresponding conductivity at a given temperature were avoided as a further check on the validity of the procedures used to correct for the influence of conductivity and related phenonema [4]. At any temperature the values of dielectric constant obtained agreed to better than 0.01 unit with respect to their mean.

In all, 60 determinations were made at 21 temperatures. Except for error resulting from isotopic contamination of the sample, which is estimated to be less than 0.005 unit, the known sources of error are similar, and their effects are comparable to those previously reported for water. (The residual uncertainty in dielectric constant as a result of any recognized source of error appears to be limited to 0.01 unit or less.)

\section{Results}

The values of the dielectric constant of the sample as measured over the range $4^{\circ}$ to $100^{\circ} \mathrm{C}$ fit the equation $\boldsymbol{\epsilon}=87.48_{2}-(0.40509) t+\left(9.638 \times 10^{-4}\right) t^{2}-$

$$
\left(1.333 \times 10^{-6}\right) t^{3}
$$

where $t$ is the temperature in degrees Celsius. The values obtained from this equation, along with the difference between these values and those measured at specific temperatures, are listed in table 1. The maximum deviation is below 0.01 unit. Values of $d \epsilon / d t$ and the temperature coefficient $(1 / \epsilon)(d \epsilon / d t)$ are listed in the remaining columns.

The data may also be represented by the relation

$$
\log _{10} \epsilon=1.94167-0.0019940 t,
$$

with a maximum deviation of 0.03 unit and an average deviation of \pm 0.02 unit in dielectric constant. However, these deviations are not random with temperature. The over-all accuracy of the values of dielectric constant listed in table 1 is considered to be \pm 0.05 unit or better and that of the temperature coefficient 1 percent or better at all temperatures. Deviation of these values from those for pure deuterium oxide as a result of isotopic contamination is estimated to be less than 0.005 unit.

TABLE 1. Dielectric constant of deuterium oxide and related

\begin{tabular}{|c|c|c|c|c|}
\hline$t$ & $\epsilon$ eq $(1)$ & $\epsilon$ eq (1) $-\epsilon$ obs. & $-d \epsilon / d t$ & $-\frac{1}{\epsilon} \frac{d \epsilon}{d t}$ \\
\hline${ }^{\circ} \mathrm{C}$ & & & & \\
\hline 4 & 85.877 & +0.007 & 0.3974 & 4. $627 \times 10^{-3}$ \\
\hline 5 & 85.480 & -.001 & .3956 & 4. 628 \\
\hline 10 & 83. 526 & +.002 & .3862 & 4. 624 \\
\hline 15 & 81. 618 & -.001 & .3771 & 4. 620 \\
\hline 20 & 79.755 & +.001 & .3681 & 4. 615 \\
\hline 25 & 77. 936 & -.001 & .3594 & 4. 611 \\
\hline 30 & 76.161 & +.002 & .3509 & 4. 607 \\
\hline 35 & 74.427 & -.001 & .3425 & 4. 602 \\
\hline 40 & 72.735 & +.002 & .3344 & 4. 597 \\
\hline 45 & 71.083 & .000 & .3265 & 4. 593 \\
\hline 50 & 69.470 & -.003 & .3187 & 4. 587 \\
\hline 55 & 67.896 & -.005 & .3112 & 4.583 \\
\hline 60 & 66.358 & -.001 & .3038 & 4. 578 \\
\hline 65 & 64.857 & +.005 & .2967 & 4. 575 \\
\hline 70 & 63. 391 & -.001 & .2898 & 4. 571 \\
\hline 75 & 61.959 & +.002 & .2830 & 4. 567 \\
\hline 80 & 60.561 & -.002 & .2765 & 4. 565 \\
\hline 85 & 59. 194 & -.003 & .2701 & 4. 563 \\
\hline $\begin{array}{l}90 \\
95\end{array}$ & $\begin{array}{l}57.859 \\
56.554\end{array}$ & $\begin{array}{l}.000 \\
.000\end{array}$ & $\begin{array}{l}.2640 \\
2581\end{array}$ & $\begin{array}{l}\text { 4. } 563 \\
\text { 4. } 564\end{array}$ \\
\hline 100 & 55.278 &,+ 006 & 2523 & 4.564 \\
\hline & 50.210 & T.000 & .2020 & 4.564 \\
\hline
\end{tabular}
data

\section{Discussion}

A direct comparison of the present data with those of Wyman and Ingalls is not too significant due to the difference in absolute reference. A comparison by means of the companion measurements. on ordinary water is possible and also advantageous because the similarity of $\mathrm{D}_{2} \mathrm{O}$ and $\mathrm{H}_{2} \mathrm{O}$ makes their difference in dielectric constant of some interest. These differences, as determined by Wyman and Ingalls, and by Malmberg and Maryott and the present data, are shown, respectively, by curves. $A$ and $B$ of figure 2. The shape of these curves seems significant in that both show distinct maxima 


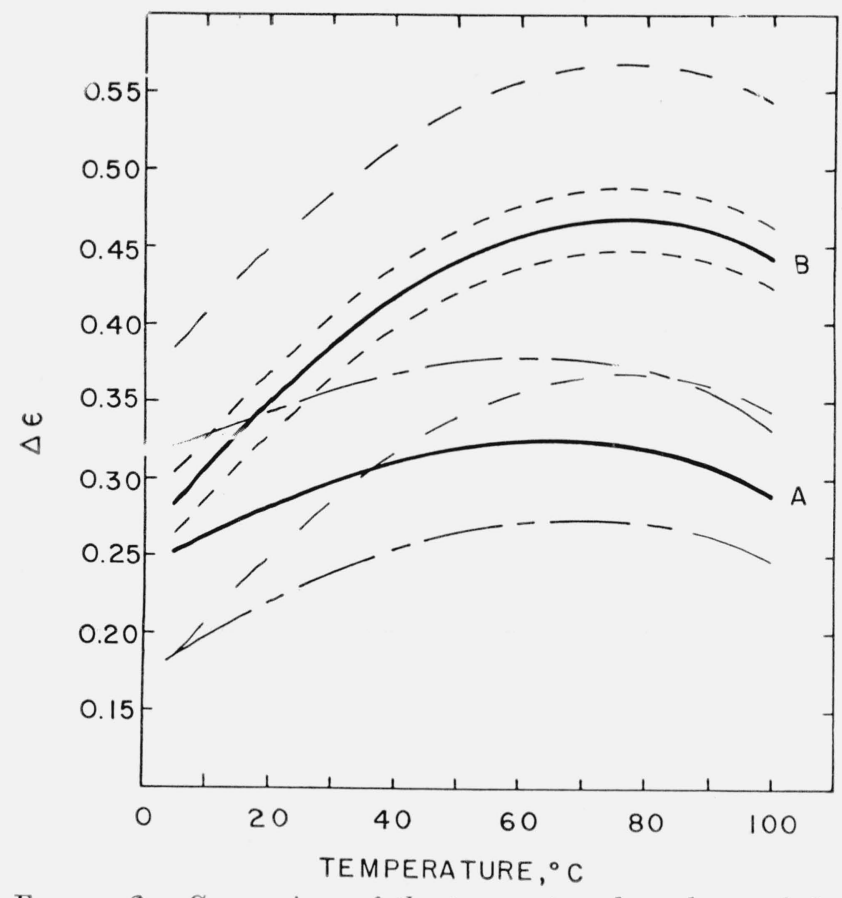

Figure 2. Comparison of the temperature-dependence of the difference in dielectric constant between $\mathrm{H}_{2} \mathrm{O}$ and $\mathrm{D}_{2} \mathrm{O}$ as determined by Wyman and Ingalls $(A)$ and by Malmberg and Maryott and the present work $(B)$.

in the same temperature range. At the same time, their lack of identity indicates that significant error exists for which correction has not been made. The differences involved are small but not negligible in view of the precision of measurement achieved. No positive explanation for the difference in $\Delta \epsilon$ is available and, as the limits of accuracy of $\Delta \epsilon$ are set by those of the parent data, it is difficult to assess its actual significance in any case. These limits are indicated in figure 2, where the bands centered about curve $B$ respectively represent the experimental reproducibility obtained and the limits of accuracy in terms of the basic data. The band centered on curve A represents the sum of the mean deviations reported for the data supporting this curve $(0.078 \%)$. A comparable band for curve B would be less than \pm 0.01 unit wide, about one-sixth or less than that for curve $A$. If unrecognized sources of error involved in the measurements supporting curve $B$ are constant, then the probable accuracy of this curve is closely related to the reproducibility of the data. It is believed that a near approach to these conditions was achieved experimentally and that the values of $\Delta \epsilon$ for curve $\mathrm{B}$ are probably accurate to \pm 0.03 unit or better.

In figure 3 , values of the temperature coefficient, $(1 / \epsilon)(d \epsilon / d t)$, obtained by Wyman and Ingalls are compared with those listed in table 1 . The values from the present data are considerably more constant with temperature, and consequently the data are more nearly represented by a logarithmic relation, such as eq (2), than are the data of Wyman and Ingalls. The agreement in temperature coefficient obtained is in general satisfactory, even though a knowledge of this

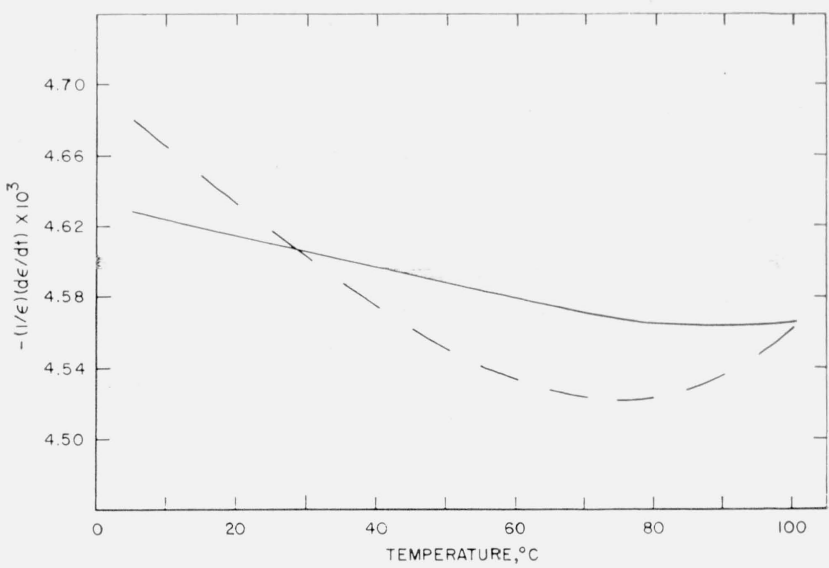

Figure 3. Temperature-dependence of the temperature coefficient of $\epsilon$ for $\mathrm{D}_{2} \mathrm{O}$.

Reported by Wyman and Ingalls. Present work.

parameter to better than 1 percent is desirable in certain thermodynamic applications. It should be noted that the temperature dependence of $(1 / \epsilon)(d \epsilon / d t)$ for the companion data on water exhibits a distinct parallelism with those on $\mathrm{D}_{2} \mathrm{O}$, indicating that the values obtained are significantly influenced by the procedures employed.

A comparison of dielectric properties can be made in terms of a "macroscopic polarization", $P$, defined by

$$
P=(\epsilon-1) V,
$$

where $V$ is the molar volume. The temperature dependence of $P$ frequently follows the relation

$$
P_{T} \approx a+b / T,
$$

where $a$ and $b$ are empirical constants and $T$ the absolute temperature. Applied to existing data on nonpolar, polar, and on "associated" polar liquids, the approximation is in many cases quite good, 1 percent or better, over wide ranges of temperature.

Values of $P$ calculated for deuterium oxide and water in accordance with eq 3 are listed in table 2 . They are based on the present values for deuterium oxide and those for water obtained previously [4]. The molar volumes used were calculated by means of the table of densities due to T. L. Chang and L. H. Tung [5]. The respective values of $18.021_{1}$ and $20.033_{9}$ were used for the molecular weights of normal water and of 100-percent deuterium oxide having 0.21 mole percent $\mathrm{O}^{18}$. The present sample of deuterium oxide does not exactly fit this description, but this is not significant for the present purpose because the effects of concentration errors are estimated to be less than 0.005 unit on the value of $\epsilon$ at any temperature. The difference in polarization, $\Delta P$, for these two compounds is always relatively less than their difference in dielectric constant. Values of $\Delta P$ are always rather small, amounting to at most about 0.6 percent around $100^{\circ} \mathrm{C}$, and the value changes sign between $15^{\circ}$ and $20^{\circ} \mathrm{C}$.

Because a graphical analysis was not sufficiently sensitive, mean values of the constants $a$ and $b$ 
corresponding to eq (4) were calculated from the values of $P$ listed in table 2 .

For $D_{2} O$,

$$
P=\frac{553,825}{T}-461.58
$$

and for $\mathrm{H}_{2} \mathrm{O}$,

$$
P=\frac{544,265}{T}-428.14
$$

TABLE 2. Macroscopic polarization of $\mathrm{H}_{2} \mathrm{O}$ and $\mathrm{D}_{2} \mathrm{O}$

\begin{tabular}{|c|c|c|c|c|c|}
\hline \multirow{2}{*}{$t$} & \multicolumn{2}{|c|}{$V_{\mathrm{cm}^{3}}$} & \multicolumn{2}{|c|}{$P_{\mathrm{em}^{3}}$} & \multirow{2}{*}{$\Delta P_{\mathrm{cm}^{3}}$} \\
\hline & $\mathrm{H}_{2} \mathrm{O}$ & $\mathrm{D}_{2} \mathrm{O}$ & $\mathrm{H}_{2} \mathrm{O}$ & $\mathrm{D}_{2} \mathrm{O}$ & \\
\hline \multicolumn{6}{|l|}{${ }^{\circ} C$} \\
\hline${ }_{3}^{0} 8$ & 18. 0235 & & $1,563.36$ & & \\
\hline $\begin{array}{l}3.8 \\
5.0\end{array}$ & $\begin{array}{l}.0211_{4} \\
.0213\end{array}$ & $\begin{array}{r}18.1240 \\
.1212\end{array}$ & $1,527.54$ & $\begin{array}{l}1,539 . \\
1,530.88\end{array}$ & -3.34 \\
\hline 10. 0 & .0260 & .1146 & $1,493.13$ & $1,494.93$ & -1.80 \\
\hline 15. 0 & .0368 & .1166 & $1,460.01$ & $1,460.52$ & -0.51 \\
\hline 20.0 & .0530 & .1253 & $1,428.05$ & $1,427.46$ & +0.59 \\
\hline 25.0 & .0741 & .1400 & $1,397.20$ & $1,395.62$ & 1. 56 \\
\hline 30.0 & .0993 & .1599 & $1,367.33$ & $1,364.92$ & 2. 41 \\
\hline 35.0 & .1288 & .1847 & 1, 338. 41 & $1,335.25$ & 3.14 \\
\hline 40.0 & .1619 & .2139 & $1,310.40$ & $1,306.57$ & 3. 83 \\
\hline 45.0 & .1988 & .2474 & $1,283.23$ & $1,278.83$ & 4. 42 \\
\hline 50.0 & .2387 & .2849 & $1,256.83$ & $1,251.97$ & 4. 88 \\
\hline 55.0 & .2820 & .3261 & $1,231.20$ & $1,225.95$ & 5. 29 \\
\hline 60.0 & .3283 & .3706 & $1,206.28$ & $1,200.67$ & 5. 65 \\
\hline 65.0 & .3779 & .4184 & $1,182.05$ & $1,176.15$ & 5.96 \\
\hline 70.0 & .4301 & .4693 & $1,158.46$ & $1,152.32$ & 6. 20 \\
\hline 75.0 & .4853 & .5235 & $1,135.50$ & $1,129.18$ & 6. 36 \\
\hline $\begin{array}{l}80.0 \\
85.0\end{array}$ & .5435 & .5807 & $1,113.11$ & $1,106.69$ & 6. 48 \\
\hline $\begin{array}{l}85.0 \\
90.0\end{array}$ & $\begin{array}{l}6044 \\
6682\end{array}$ & .6410 & $1,091.32$ & $\begin{array}{l}1,084.80 \\
1,063\end{array}$ & 6.54 \\
\hline 90.0 & .6682 & .7042 & $1,070.04$ & $1,003.50$ & \\
\hline 95.0 & .7346 & .7703 & $1,049.27$ & $1,042.76$ & 6. 49 \\
\hline 100.0 & .8038 & .8391 & $1,028.94$ & $1,022.55$ & 6.33 \\
\hline 101. 4 & .8238 & .8591 & - & - & - \\
\hline
\end{tabular}

$$
P=(\epsilon-1) V
$$

The agreement of the values of $P$ calculated by these equations with those listed in table 2 is shown in figure 4. In only one instance is the deviation greater than 0.1 percent, and the mean deviations are 0.03 and 0.06 percent, respectively. The error associated with these calculations is controlled by the accuracy of the values of dielectric constant. This agreement is therefore very satisfactory as a support for the validity of eq 4. If this relation can be sufficiently well substantiated for a broad range of pure liquids, it will be useful for the interpolation and prediction of polarization with temperature as well as for possible identification of anomolous behavior in liquids.

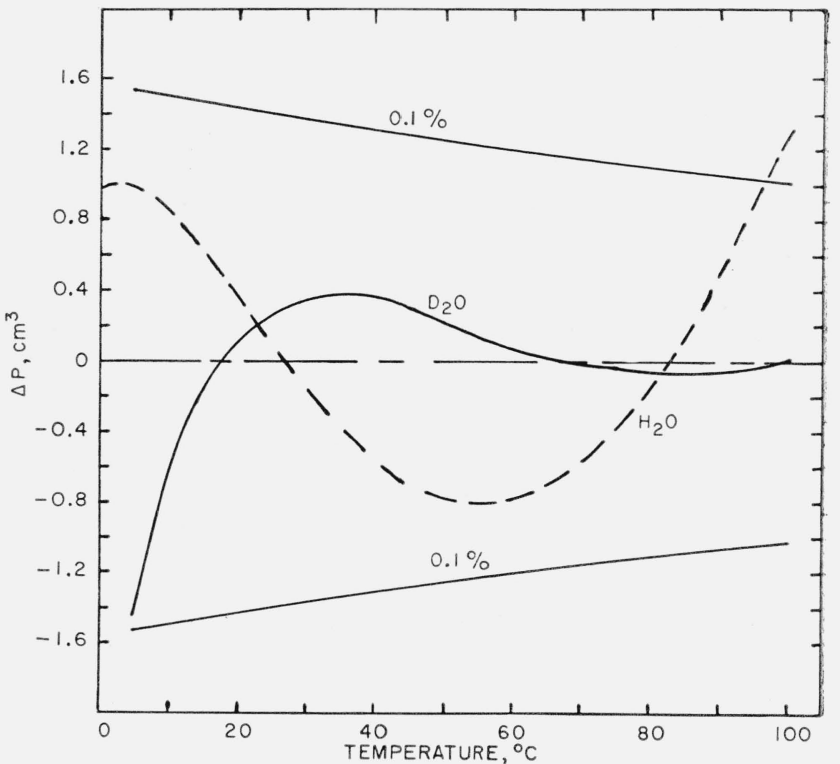

Figure 4. The difference between calculated values of $P[e q$ (5) or eq (6)] and measured values $((\epsilon-1) V)$ plotted as a function of temperature.

\section{References}

[1] J. Wyman and E. N. Ingalls, J. Am. Chem. Soc. 60, 1182 (1938).

[2] J. Wyman, Phys. Rev. 35, 623 (1930).

[3] C. G. Malmberg and A. A. Maryott, J. Research NBS 45, 299 (1950) RP2137.

[4] C. G. Malmberg and A. A. Maryott, J. Research NBS 56, 1 (1956) RP2641.

[5] T. L. Chang and L. H. Tung, Chinese J. Phys. 7, 230 (1949).

Washington, November 12, 1957. 